\title{
DISTANT TRAVELS OF TREE SWALLOWS OF THE PRAIRIE PROVINCES, 1968-1992
}

DONALD J. STILES, 201 Lake Wapta Rise Southeast, Calgary, Alberta, T2J 2M9, and MARY I. HOUSTON, 863 University Drive, Saskatoon, Saskatchewan.

S7N 0J8

The small sample of banding recoveries obtained to date suggests that Tree Swallows from Alberta and Saskatchewan follow a consistent and relatively narrow path of migration from the Canadian prairies to the Gulf coast and southern Atlantic coast, where some of them winter. If one were to draw a line from each banding point to the corresponding recovery point, assuming that the swallows followed a reasonably straight line, the lines representing those banded near Edmonton would become confused with lines from banding points along the Saskatoon and Indian Head banding trails, resulting in a confusing mesh of inseparable, nearly parallel lines. For this reason we deleted such lines from Figure 1.

To obtain the 26 out-of-province recoveries reported (Figure 1 and Table 1), it was necessary to band a prodigious number of swallows, about 55,000 over 25 years. For example, from 11,789 Tree Swallows banded near Saskatoon, 1968-1991, Mary Houston has had 28 recoveries to date, a rate of only $0.002 \%$ (two per thousand), including seven recoveries from beyond Saskatchewan. ${ }^{2}$ Before 1987, published distant recoveries from the Saskatoon area were all of birds banded as nestlings; three were in North Dakota and one at Somerset, Manitoba, all four in August. $^{2}$ Of the 11,600 swallows he banded near Indian Head, Saskatch- ewan, Lorne Scott had one found dead in North Dakota two months after banding and one shot in Minnesota one year later, respectively. ${ }^{2}$ Alberta banding of this species has included 10,351 swallows banded by Erhard (Hardy) Pletz of Edmonton; 8,794 by J. Cam Finlay; 5,684 by Don Stiles of Calgary and his subpermittees; 2,700 by the Beaverhills Bird Observatory; 2,084 by Edgar $T$. Jones; 1,430 by Helen Trefry; and 800 by Robert E. Danner. This paper is the first comprehensive report of recoveries from the extensive banding effort in Alberta, and adds three more distant recoveries to the list of swallows banded in Saskatchewan.

Results The Tree Swallow migration for both immatures (22) and adults (4) follows the common and expected southeasterly route for most small birds from Alberta and Saskatchewan, but the plotted course is a surprisingly consistent arc between $110^{\circ}$ and $139^{\circ}$ southeasterly for $\mathrm{Al}-$ berta swallows and between $113^{\circ}$ and $150^{\circ}$ for Saskatchewan swallows (Figure 1 and Table 2). Six of the 11 direct recoveries had an almost identical course of between $110^{\circ}$ and $117^{\circ}$ southeast, and 7 of the 14 recovered in subsequent years followed a similar course of between $112^{\circ}$ and $119^{\circ}$. Seven, with a Manitoba swallow, ended up in the northeast corner of North Dakota. Only five swallows, those destined 


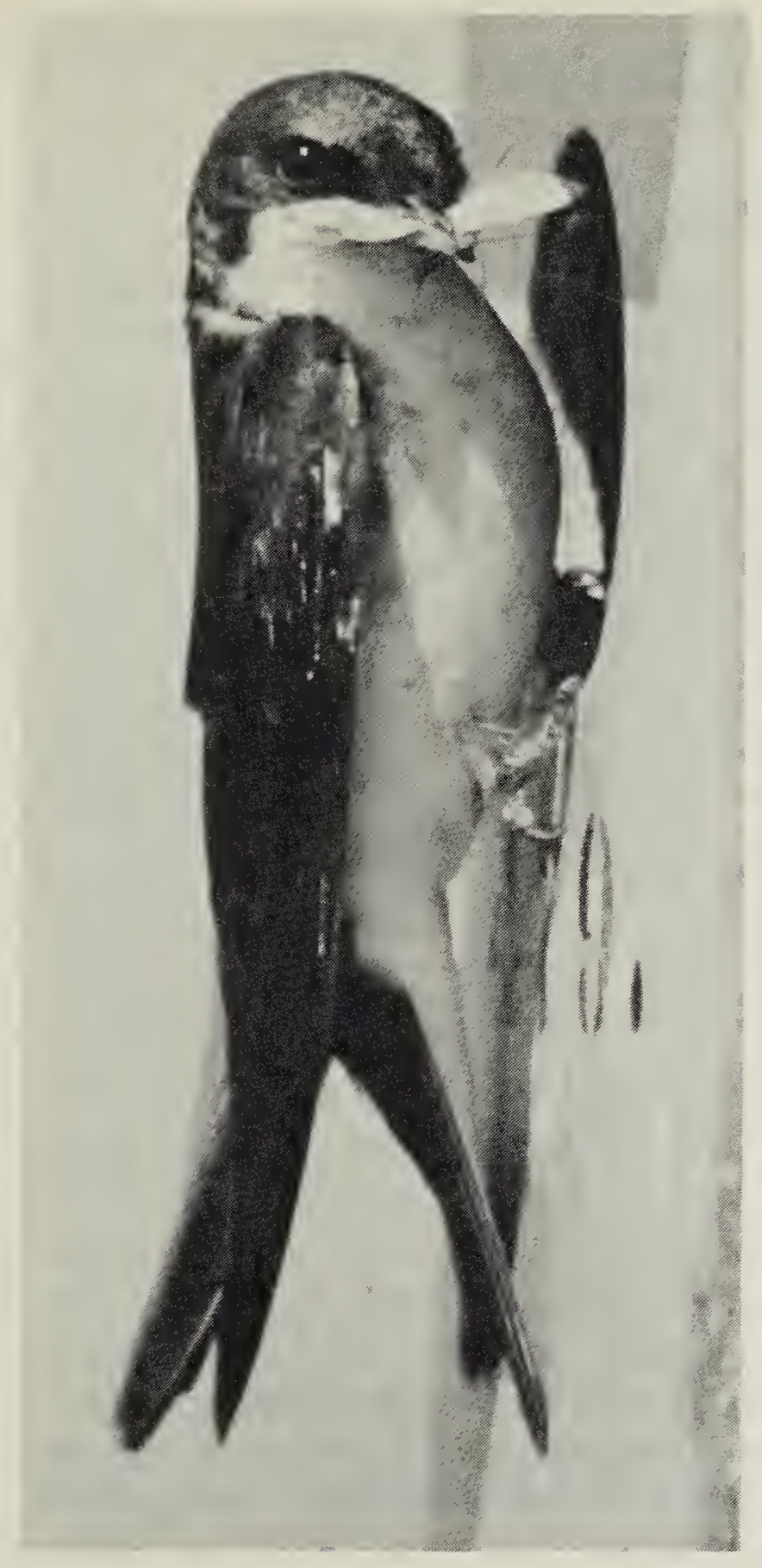

Tree Swallow at nest

John Lowe

for Missouri, Mississippi and Louisiana (three originating from Alberta locations closer to Calgary and two from Saskatoon), deviated a relatively few degrees more to the south, four of them reaching the strip of coastline where relatively few swallows remain through the winter. Two other swallows reached the easternmost portion of this coast in southeastern South Carolina and Georgia. The five from Alberta all travelled more than $3,000 \mathrm{~km}$ and the one from Saskatchewan over 2,600 km (Table 2).

Although many adult swallows return to use the same or a nearby nest box, recoveries of two swallows banded as breeding adults reveal surprisingly long distances between the nesting site in a given year and that of a subsequent year. ${ }^{2}$ This suggests that some individuals at least use nest sites at a considerable distance from those occupied previously. One swallow, killed by a car in North Dakota in early June, was $1,085 \mathrm{~km}$ from its Edmonton area nesting site where it had been banded as a breeding adult by Cam Finlay almost exactly one year earlier. Another breeding swallow banded by Robert Taylor at Delta, Manitoba was a "wrong-way Corrigan"; it followed the flight corridor but in the opposite direction from a nest box near Delta, Manitoba, to another near Spy Hill, Saskatchewan, a dispersal of $265 \mathrm{~km}$ over two years.

Even more dramatic were the distances between the nests in which two swallows were raised and the boxes in which they in turn raised offspring. A swallow that was fledged in the Edmonton area, banded by Cam Finlay, was caught nesting in a box in Wisconsin four years later, a dispersal of $1,965 \mathrm{~km}$. An Edmonton area swallow banded by Hardy Pletz was shot with a BB gun pellet the next June in North Dakota, 1,125 km to the southeast of where it was raised.

Other individual swallows are of special interest because of evidence about the locations reached by a given date in the year of banding. A nestling swallow banded on 27 June by Helen Trefry near Wainwright, Alberta, flew to Minnesota by 6 August. An adult female swallow, banded by Edgar Jones at the bird's nest box in Alberta on the last day of May, reached Minnesota by 4 August. A nestling Saskatchewan swallow banded by Mary Houston on 2 July reached Missouri by 2 September. 


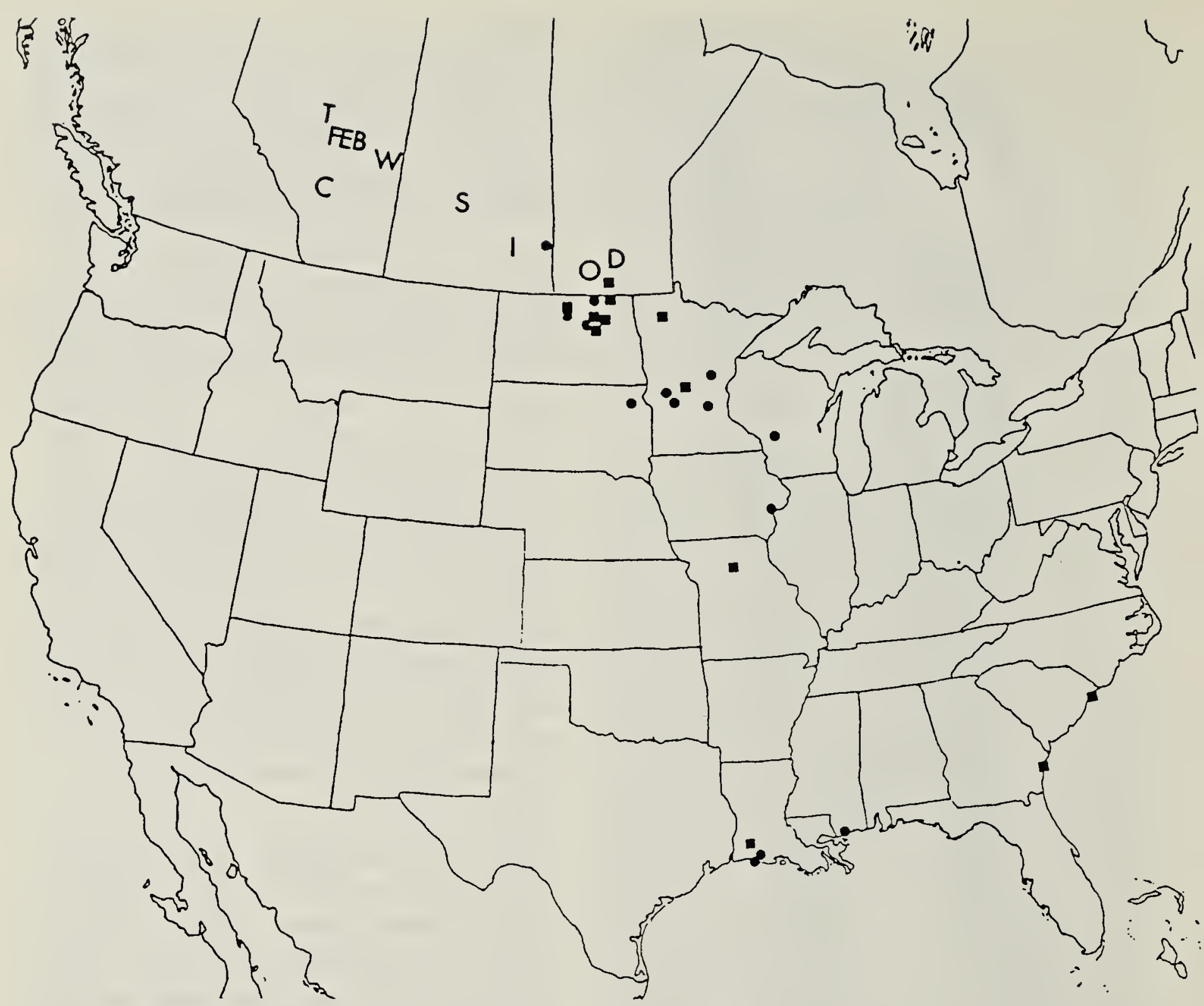

Figure 1: - direct recoveries, same year as banded. - indirect recoveries, in subsequent years. Banding localities: B - Beaverhill Lake, Alberta; C - Calgary, Alberta; D Delta, Manitoba; E - Edmonton, Alberta; F - Fort White Earth, Alberta; I - Indian Head, Saskatchewan; O - Oak Lake, Manitoba; S - Saskatoon, Saskatchewan; T - Thunder Lake, Alberta; W - Wainwright, Alberta.

Of equal interest is the manner of recovery of the 26 swallows recovered outside the province where they were banded. Ten were found dead with no obvious cause of death; one dropped dead in the sight of ecology professor Stuart Pimm and his students on a field course at Sapelo, Georgia, where the sand dunes were covered by tens of thousands of exhausted and perhaps starving Tree Swallows on their way north on 15 March. Elsewhere, three swallows were shot and killed by boys with pellet guns, two were caught by a dog and one by a cat. Two were injured, two (mentioned above) were caught alive in a far distant nest box, one was killed by a car, another was temporarily tangled in a twig and one was killed by a power transmission line. One swallow met its death in a more dramatic manner. A nestling, 2021-67115, banded in Blackstrap Causeway box 26 in a brood of six by Mary Houston on 3 July 1989, was killed by an airplane at Lake Charles Regional Airport, Lake Charles, Louisiana, 18 December 1989, $2,635 \mathrm{~km}$ away.

Even more noteworthy were the bands from two swallows found during a Barn Owl pellet study by Jennifer Coulson (pers. comm.) at the Rockefeller Wildlife Refuge, on 
Table 1. TREE SWALLOWS BANDED IN THE PRAIRIE PROVINCES AND RECOVERED IN A DIFFERENT STATE OR PROVINCE.

\begin{tabular}{||l|c|c|c|c|}
\hline \multirow{2}{*}{} & \multicolumn{4}{|c|}{ Banded in } \\
\cline { 2 - 5 } & Alberta & Saskatchewan & Manitoba & Total \\
\hline Recovered in & & & & 1 \\
\hline Georgia & 1 & & & 1 \\
\hline lowa & & 1 & & 3 \\
\hline Louisiana & 2 & 1 & & 1 \\
\hline Manitoba & & 1 & & 6 \\
\hline Minnesota & 5 & 1 & & 1 \\
\hline Mississippi & 1 & & & 8 \\
\hline Missouri & 3 & 1 & & 1 \\
\hline North Dakota & 1 & 4 & 1 & 1 \\
\hline Saskatchewan & 1 & & 1 & 1 \\
\hline South Carolina & 1 & & & 26 \\
\hline South Dakota & 15 & & & \\
\hline Wisconsin & & 9 & & \\
\hline Total & & & & 1 \\
\hline
\end{tabular}

the southwest coast of Louisiana near Grand Chenier. The first, 201091554, a nestling in a brood of seven, was banded $13 \mathrm{mi}$. east and $2 \mathrm{mi}$. north of Didsbury, Alberta, by Donald Stiles on 25 June 1988; the band was found in a Barn Owl pellet on 23 August 1991. Another, 206153259, was banded near Edmonton by R.E. Danner on 1 July 1989; the band was recovered in a pellet analyzed on 28 July 1992. There is no estimate of when either pellet had been coughed up, but in her study Coulson found skeletons of 544 vertebrates, including 344 birds, of which 18 were Tree Swallows. One suspects that both swallows were captured by the owl and the pellet regurgitated much earlier in the year, perhaps while the swallows were roosting in early spring.

Discussion Butler's 1988 review of all North American banding of Tree Swallows noted that there had been only 293 recoveries from banding of 802,662 across North America, or $0.0003 \%$, three from every 10,000 banded. Of these, only 41 recoveries were outside the breeding season and more than $120 \mathrm{~km}$ from the banding site. 'Butler's oversimplified map depicts a single banding site in Alberta with a recovery in South Carolina, and a Saskatchewanbanded recovery in Minnesota, but his legend states that "Some symbols represent more than one banding location and recovery site." Butler's statement, from evidence to date, that "Swallows from the Canadian prairies ... appear to migrate mostly along the Mississippi River Valley to their winter quarters in the southern USA and Central America," is a surmise based on extrapolation. Two of our swallows moved, directly or indirectly, east of the Mississippi to the Atlantic coast. Surprisingly, there is as yet no record of a banded swallow from the prairie provinces being recovered in the presumed main wintering areas of Mexico and Central America. ${ }^{3}$

One of the largest Tree Swallow staging areas in Louisiana is near Edgard, west of New Orleans, where a million or more Tree Swallows congregate from late November to early December at a sugar mill before 
Table 2. OUT-OF-PROVINCE RECOVERIES OF TREE SWALLOWS BANDED IN PRAIRIE PROVINCES, 1965-1992

\begin{tabular}{|c|c|c|c|c|c|c|}
\hline \multicolumn{7}{|c|}{ Banding } \\
\hline \multirow[b]{2}{*}{ Bander } & \multirow[b]{2}{*}{ Band No. } & \multirow[b]{2}{*}{ Age $^{\star}$} & \multicolumn{3}{|c|}{ Where Banded } & \multirow{2}{*}{$\begin{array}{c}\text { When } \\
\text { Date } \\
(\mathrm{y} / \mathrm{m} / \mathrm{d})\end{array}$} \\
\hline & & & Lat. & Long. & {$\left[\begin{array}{c}\star \star * \\
\text { Loc. }\end{array}\right.$} & \\
\hline \multicolumn{7}{|c|}{ Alberta } \\
\hline E.T. Jones & $0800-15555$ & $\mathrm{AdF}$ & 53.2 & 113.0 & $E$ & $72 / 05 / 31$ \\
\hline E.T. Jones & $2021-62657$ & $\mathrm{~L}$ & 53.2 & 112.5 & $E$ & $89 / 06 / 30$ \\
\hline J.C. Finlay & $1041-85067$ & $\mathrm{~L}$ & 54.0 & 114.4 & $T$ & 73/07/01 \\
\hline J.C. Finlay & 0820-27269 & $\mathrm{L}$ & 53.2 & 113.1 & $E$ & $75 / 06 / 24$ \\
\hline J.C. Finlay & 0880-26155 & $\mathrm{L}$ & 53.0 & 113.4 & $E$ & $77 / 07 / 09$ \\
\hline J.C. Finlay & 0890-49655 & AdF & 53.2 & 114.1 & $\mathrm{~F}$ & $80 / 06 / 12$ \\
\hline J.C. Finlay & $0890-49857$ & $\mathrm{~L}$ & 53.1 & 113.3 & $E$ & $80 / 07 / 04$ \\
\hline H. Trefry & $0940-13050$ & $\mathrm{~L}$ & 52.5 & 110.5 & W & $85 / 06 / 27$ \\
\hline H. Trefry & $2011-78554$ & $L$ & 52.5 & 111.0 & $W$ & $87 / 07 / 02$ \\
\hline E. Pletz & 0980-29944 & $L$ & 53.3 & 113.2 & $E$ & $85 / 06 / 20$ \\
\hline E. Pletz & $2051-98045$ & $L$ & 53.3 & 113.2 & $E$ & $87 / 06 / 24$ \\
\hline D.J. Stiles & $2010-91554$ & $\mathrm{~L}$ & 51.4 & 113.4 & $\mathrm{C}$ & $88 / 06 / 25$ \\
\hline D.J. Stiles & $2031-62019$ & AdF & 51.2 & 114.2 & $\mathrm{C}$ & $90 / 06 / 30$ \\
\hline Beaverhill Obs. & $2061-50071$ & $\mathrm{~L}$ & 53.2 & 112.3 & $\mathrm{~B}$ & $89 / 07 / 03$ \\
\hline R.E. Danner & 2061-53259 & $\mathrm{L}$ & 53.1 & 113.4 & $E$ & $89 / 07 / 01$ \\
\hline \multicolumn{7}{|c|}{ Saskatchewan } \\
\hline R.L. Scott & 0730-04491 & L & 50.2 & 103.2 & 1 & $69 / 07 / 06$ \\
\hline R.L. Scott & $0830-08363$ & L & 50.3 & 104.0 & 1 & $75 / 06 / 27$ \\
\hline M.I. Houston & 0830-11930 & $\mathrm{L}$ & 51.5 & 106.3 & $S$ & $75 / 06 / 29$ \\
\hline M.I. Houston & $0830-17273$ & $\mathrm{~L}$ & 51.5 & 106.4 & $S$ & $76 / 06 / 21$ \\
\hline M.I. Houston & 0880-41966 & $\mathrm{L}$ & 51.5 & 106.4 & $S$ & \begin{tabular}{|l|}
$77 / 07 / 08$ \\
\end{tabular} \\
\hline M.I. Houston & $2000-06162$ & $L$ & 51.4 & 106.2 & $S$ & $84 / 06 / 30$ \\
\hline M.I. Houston & $2010-88374$ & $L$ & 51.5 & 106.3 & $s$ & $85 / 06 / 25$ \\
\hline M.I. Houston & $2011-85001$ & $\mathrm{~L}$ & 51.5 & 106.4 & $S$ & $87 / 07 / 02$ \\
\hline M.I. Houston & $2021-67115$ & $L$ & 51.4 & 106.2 & $S$ & $89 / 07 / 03$ \\
\hline \multicolumn{7}{|c|}{ Manitoba } \\
\hline R.R. Taylor & $0520-49136$ & AdU & 50.1 & 98.1 & $\mathrm{D}$ & $58 / 07 / 27$ \\
\hline D.R. Hatch & $1080-63570$ & $\mathrm{~L}$ & 49.4 & 100.3 & $\mathrm{O}$ & $69 / 06 / 21$ \\
\hline \multicolumn{3}{|c|}{$\begin{array}{l}\text { `Age } \\
\text { L - Local, unable to fly } \\
\text { AdF - Adult female } \\
\text { AdU - Adult, sex unknown }\end{array}$} & \multicolumn{4}{|c|}{$\begin{array}{l}\text { *Localities (Loc.) where banded (see map) } \\
\text { B - Beaverhill Lake, Alberta } \\
\text { C - Calgary, Alberta } \\
\text { D - Delta, Manitoba } \\
\text { E - Edmonton, Alberta } \\
\text { F - Fort White Earth, Alberta } \\
\text { I - Indian Head, Saskatchewan } \\
\text { O - Oak Lake, Manitoba } \\
\text { S - Saskatoon, Saskatchewan } \\
\text { T - Thunder Lake, Alberta } \\
\text { W - Wainwright, Alberta }\end{array}$} \\
\hline
\end{tabular}


Recoveries

\begin{tabular}{|c|c|c|c|c|c|c|}
\hline \multicolumn{3}{|c|}{ Where Recovered } & \multirow{2}{*}{$\begin{array}{c}\text { When } \\
\text { Date } \\
(\mathrm{y} / \mathrm{m} / \mathrm{d})\end{array}$} & \multirow{2}{*}{$\frac{\text { How }}{\star \star \star \star}$} & \multirow{2}{*}{$\begin{array}{c}\begin{array}{c}\text { Distance } \\
\text { from banding } \\
\text { site }\end{array} \\
(\mathrm{km}) \\
\end{array}$} & \multirow{2}{*}{\begin{tabular}{|l} 
Direction \\
(degrees)
\end{tabular}} \\
\hline Lat. & Long. & $\begin{array}{l}\star \star \star \\
\text { Loc. }\end{array}$ & & & & \\
\hline 45.4 & 94.5 & $\mathrm{MN}$ & $72 / 08 / 04$ & 00 & 1560 & SE 116 \\
\hline 46.0 & 93.3 & $M N$ & $90 / 08 / 20$ & 00 & 1605 & SE 113 \\
\hline 33.3 & 78.5 & SC-w & $73 / 10 / 31$ & 57 & 3610 & SE 115 \\
\hline 45.1 & 95.2 & $\mathrm{MN}$ & $79 / 08 / 04$ & 00 & 1575 & SE 118 \\
\hline 48.3 & 100.4 & ND & $77 / 08 / 08$ & 00 & 1040 & SE 114 \\
\hline 48.3 & 100.4 & ND & $81 / 06 / 08$ & 14 & 1085 & SE 114 \\
\hline 44.0 & 90.3 & WI & $84 / 06 / 18$ & 88 & 1965 & SE 113 \\
\hline 48.1 & 95.5 & $\mathrm{MN}$ & $85 / 08 / 06$ & 00 & 1180 & SE 110 \\
\hline 30.1 & 89.1 & MS-w & $91 / 11 / 09$ & 00 & 3085 & SE 136 \\
\hline 48.4 & 99.1 & ND & $86 / 06 / 04$ & 01 & 1125 & SE 113 \\
\hline 31.2 & 81.1 & GA-w & $88 / 03 / 16$ & 00 & 3560 & SE 121 \\
\hline 29.4 & 92.4 & LA-w & $91 / 08 / 23$ & 09 & 3000 & SE 137 \\
\hline 45.1 & 97.3 & $\mathrm{SD}$ & $92 / 07 / 28$ & 01 & 1420 & SE 112 \\
\hline 45.3 & 95.4 & $\mathrm{MN}$ & $90 / 06 / 28$ & 12 & 1495 & SE 119 \\
\hline 29.4 & 92.4 & LA-W & $92 / 07 / 28$ & 09 & 3125 & SE 139 \\
\hline 48.0 & 98.5 & ND & $69 / 09 / 41$ & 00 & 420 & SE 127 \\
\hline 45.0 & 93.5 & MN & $76 / 07 / 23$ & 01 & 975 & SE 125 \\
\hline 48.1 & 99.1 & ND & $75 / 08 / 30$ & 03 & 665 & SE 125 \\
\hline 48.5 & 98.3 & ND & $76 / 08 / 12$ & 03 & 670 & SE 117 \\
\hline 49.2 & 98.3 & $\mathrm{MB}$ & 77/08/09 & 54 & 640 & SE 113 \\
\hline 41.2 & 91.0 & IA & $87 / 09 / 09$ & 00 & 1640 & SE 129 \\
\hline 47.4 & 99.1 & ND & $85 / 08 / 26$ & 00 & 700 & SE 129 \\
\hline 39.3 & 93.0 & $\mathrm{MO}$ & $87 / 09 / 02$ & 11 & 1730 & SE 137 \\
\hline 30.1 & 93.0 & LA-W & $89 / 12 / 18$ & 39 & 2635 & SE 150 \\
\hline 50.3 & 101.5 & SK & $60 / 05 / 30$ & 88 & 265 & NW 265 \\
\hline 48.0 & 99.0 & ND & $75 / 07 / 19$ & 11 & 215 & SE 149 \\
\hline \multicolumn{4}{|c|}{${ }^{\star \star \star}$ - "w" means on wintering grounds } & \multicolumn{3}{|c|}{$\begin{array}{l}\star \star \star \star \text { Codes for how found } \\
00 \text { - found dead (10) } \\
01 \text { - shot ( } 3 \text { ) } \\
03 \text { - injured (2) } \\
09 \text { - killed by owl (2) } \\
11 \text { - caught by dog (2) } \\
12 \text { - caught by cat (1) } \\
14 \text { - killed by automobile (1) } \\
39 \text { - killed by airplane (1) } \\
54 \text { - electrocuted (1) } \\
57 \text { - entangled in twig, released (1) } \\
88 \text { - nesting (2) } \\
\text { (total = 26) }\end{array}$} \\
\hline
\end{tabular}


settling in nearby sugar cane fields each night: "About an hour before dusk ... birds begin arriving from all directions ... concentrate in a huge mass ... hovering ... a minute before they descend, the whole group begins to swirl forming two or three funnel clouds." ${ }^{4}$ In 1978, the swallows frequented their cane field roost until mid-January but most years they leave for some unknown destination by mid-December. ${ }^{4}$

Acknowledgements We thank Jennifer Coulson for sharing information concerning her Barn Owl study paper; Bob Danner, G.R. Ebel, Cam Finlay, Edgar Jones, Hardy Pletz, Lorne Scott, Robert R. Taylor and Helen Trefry for permission to use their recovery data; and Ronald J. Stein for his article concerning the
December roost in Louisiana. Useful criticism was provided by Margaret Belcher, Bernie Gollop, Stuart Houston, and Robert Cohen.

1. BUTLER, R.W. 1988. Population dynamics and migration dynamics of Tree Swallows, Tachycineta bicolor, in North America. J. Field Ornithol. 59:395-402.

2. HOUSTON, M.I. and C.S. HOUSTON. 1987. Tree Swallow banding near Saskatoon, Saskatchewan. North Am. Bird Bander 12:103-108.

3. ROBERTSON, R.J., B.J. STUTCHBURY and R. COHEN. 1992. Tree Swallow. In: The birds of North America, No. 11 (A. S. Poole, P. Stettenheim, and F. Gill, eds.). Philadelphia: The Academy of Natural Sciences.

4. STEIN, R. 1993. Tree Swallow staging area. Louisiana Ornithological Society News 154:1-3.

Feeding birds: In the past decade, this has become a popular hobby. Contrary to popular opinion, putting out seed will not disrupt migratory patterns, reports the Chicago Tribune. Birds tend to go where they are supposed to be, says Steve Lewis of the U.S. Fish and Wildlife Service. Globe and Mail. 8 March 1994.

\section{ERRATA}

In the article "Butterflies of the Peace River region of Alberta and British Columbia" (Blue Jay 52:71), Table 1 (p. 87) was missing the localities for the " 8 " series of locations on the map. The localities are:

$8 \mathrm{a}-10 \mathrm{~km}$ NE of Paddle Prairie

$8 b-21 \mathrm{~km} \mathrm{NE}$ of Paddle Prairie

$8 c$ - La Crete Ferry

8d $-7 \mathrm{~km} \mathrm{NE}$ of La Crete Ferry

$8 \mathrm{e}$ - Buffalo fire tower, $15 \mathrm{~km}$ SE of Buffalo Head Prairie

$8 f-10 \mathrm{~km}$ SW of High Level

$8 \mathrm{~g}-6 \mathrm{~km} \mathrm{~W}$ of High Level

(no site $8 \mathrm{~h}$ appears on the map)

$8 \mathrm{i}$ - Fort Vermilion Bridge 